\title{
SENTIDOS DE SEXUALIDADE NOS ANAIS DOS ENCONTROS NACIONAIS DE ENSINO DE BIOLOGIA (2005-2016)
}

\author{
Raquel Pinho ${ }^{1}$ \\ Felipe Bastos ${ }^{2}$
}

\section{RESUMO}

Este artigo objetiva compreender os sentidos de sexualidade atribuídos às produções científicas apresentadas no Encontro Nacional de Ensino de Biologia (ENEBIO). Todos os 2.517 trabalhos apresentados nas seis edições do encontro foram triados através de ferramentas de busca e 107 foram selecionados de acordo como recorte desejado: temas relativos a sexualidade, tais como sexo, gênero, DST, gravidez, entre outros. Concluímos que a sexualidade é uma área emergente e em consolidação nos encontros, visto o aumento de trabalhos relacionados ao longo dos anos. Os artigos foram majoritariamente escritos por autoras mulheres, de universidades públicas. De modo geral, as pesquisas têm como foco estudantes e professoras da educação básica, principalmente do ensino fundamental. Quantitativamente, observamos o predomínio da abordagem sociológica da sexualidade, mas também foram analisadas abordagens biológicas, psicológicas e éticas. Por fim, traçamos algumas considerações sobre a importância de se analisar o campo, tanto para a pesquisa quanto para a docência.

PALAVRAS-CHAVE: Sexualidade. Gênero. Evento científico. ENEBIO.

Meanings of sexuality in annals of Encontros Nacionais de Ensino de Biologia (2005-2016)

\footnotetext{
${ }^{1}$ Doutora em Educação pela Pontifícia Universidade Católica do Rio de Janeiro (PUC-Rio). Professora no Colégio Teresiano e na Universidade Federal do Rio de Janeiro, Rio de Janeiro, Rio de Janeiro, Brasil. E-mail: raquel.aps@gmail.com.

${ }^{2}$ Mestre em Educação pela Pontifícia Universidade Católica do Rio de Janeiro (PUC-Rio). Professor no Colégio de Aplicação da Universidade Federal de Juiz de Fora (CAp/UFJF), Juiz de Fora, Minas Gerais, Brasil. E-mail: felipe.bastos@ufjf.edu.br.
} 


\begin{abstract}
This article aims to perceive the meanings of sexuality attributed to the scientific productions presented at the Encontro Nacional de Ensino de Biologia (ENEBIO). All 2,517 papers presented in the six editions of the meeting were screened using search tools and 107 were selected according to the desired scope: sexuality related themes, such as sex, gender, STD, pregnancy, amongst others. We conclude that sexuality is an emergent area under consolidation in the meetings, since its related articles shows a quantitative increase over the years. The articles were written mostly by female authors and from public universities. In general, research focuses on basic education teachers and students, especially elementary education. Quantitatively, there is a predominance of the sociological approach of sexuality, but biological, psychological and ethical approaches were also analyzed. Finally, we draw some considerations on the importance of analyzing the sexuality area, both for research and for teaching.
\end{abstract}

KEYWORDS: Sexuality. Gender. Scientific meeting. ENEBIO.

$$
* * *
$$

Ao contrário do que se pensa normalmente, educar para a tolerância não é pouco. Educar para a tolerância é uma questão de justiça que visa assegurar, numa sociedade plural, a maior multiplicidade possivel de ofertas de vida feliz condizentes com a estatura moral que os tempos atuais exigem.

Marcelo Andrade

\title{
Introdução
}

O presente artigo tem como objetivo analisar os diversos sentidos que o tema da sexualidade assume nas produções textuais das seis edições ocorridas do Encontro Nacional de Ensino de Biologia (ENEBIO). A escolha por analisar o ENEBIO se dá pela sua importância no campo de divulgação, reflexão e pesquisa sobre o ensino de Biologia. Assim como os Encontros Regionais de Ensino de Biologia (EREBIO), o ENEBIO valoriza a participação não somente de pesquisadoras ${ }^{3}$ e professoras universitárias,

\footnotetext{
${ }^{3}$ A regra gramatical da língua portuguesa que define o masculino como elemento neutro em substantivos e adjetivos foi deliberadamente invertida para o feminino como referência ao neutro, independentemente do sexo dos sujeitos ao
} 
mas também de professoras da educação básica e estudantes de graduação, fomentando diversos debates sobre o cotidiano escolar. O ENEBIO é, certamente, um dos principais encontros acadêmicos nacionais da área do ensino de Ciências Naturais e Biologia que privilegia a socialização e o debate de pesquisas e de relatos de experiências docentes entre as interlocutoras acima.

O ENEBIO é promovido pela Associação Brasileira de Ensino de Biologia (SBEnBio) ${ }^{4}$, uma associação civil de caráter científico e cultural, sem fins lucrativos, criada em 1997 no VI Encontro Perspectivas do Ensino de Biologia (EPEB), na Faculdade de Educação da Universidade de São Paulo (USP), e atualmente organizada em uma diretoria nacional e seis diretorias regionais. A SBEnBio atua não somente na promoção de eventos acadêmicos, mas também se propõe a atuar como fórum de debate entre profissionais ligadas ao ensino de Biologia, discutir a formulação, execução e avaliação de políticas públicas de educação e apoiar e promover a formação continuada dos profissionais que atuam no ensino de Ciências Naturais e Biologia, dentre outros objetivos, apresentados no art. $2^{\circ}$ do estatuto ${ }^{5}$.

Os encontros nacionais promovidos pela SBEnBio acontecem concomitantemente aos regionais, como pode ser observado no Anexo $1^{6}$. Podemos constatar que existe uma discrepância de produção entre as seis Unidades Regionais que estruturam a associação: as Regionais 2 (RJ/ES), 3 (PR/SC/RS) e 5 (Nordeste) apresentam uma história mais intensa de organizações de encontros sobre o ensino de Biologia nos estados participantes; as Regionais 1 (SP/MS/MT) e 4 (MG/GO/TO/DF) iniciaram a atuação mais recentemente e possuem um hiato mais marcado entre as datas dos encontros; a Regional 6 (Norte) não consta na análise, pois não havia organizado nenhum evento nacional até 2017.

qual o termo se refere. Seguindo esta lógica, os substantivos e adjetivos usados no masculino neste texto ocorrem somente em referência específicas a sujeitos masculinos (Felipe BASTOS, 2015).

${ }^{4}$ Para mais informações: 〈http://www.sbenbio.org.br〉. Acesso em: 19 fev. 2018.

${ }^{5}$ Disponível em: 〈http://www.sbenbio.org.br/estatuto $>$. Acesso em: 19 fev. 2018.

${ }^{6}$ Esse levantamento foi realizado com base nos eventos que já haviam acontecido até janeiro de 2017. Informações de encontros posteriores a essa data não participam desta análise. 
O primeiro EREBIO, organizado pela Regional 2, aconteceu em 2001 na cidade de Niterói (RJ), enquanto que o primeiro ENEBIO, organizado pela mesma regional, foi realizado em 2005, na cidade do Rio de Janeiro. Desde então, os encontros nacionais vêm sendo realizados de forma constate e se expandindo. Assim, tanto pela persistência temporal quanto pela relevância acadêmica, a análise das produções textuais selecionadas por estes encontros pode trazer informações sobre diversos assuntos privilegiados - ou não - por profissionais ligadas ao ensino de Biologia, tal como ocorre com a temática do gênero e da sexualidade.

Ainda que possam ser relacionados, gênero e sexualidade são categorias de análise distintas. Michel Foucault7, em A história da sexualidade I-A vontade de saber, afirma que "entre o Estado e o indivíduo, o sexo tornou-se objeto de disputa, e disputa pública" (2009, p. 29). Em concordância ao filósofo, entendemos que a sexualidade como um dispositivo, ou seja, conjunto de discursos, práticas e instituições que se modifica ao longo do tempo e atua no gerenciamento e controle de corpos, de modos de ser e das populações. Os dispositivos organizam "estratégias de relações de força sustentando tipos de saber e sendo sustentadas por eles" (FOUCAULT, 2000, p. 246), de modo que a sexualidade está inscrita num jogo de poder, relacionada com certos tipos de saberes, que terá "efeitos produzidos no corpo, nos comportamentos, nas relações sociais" (FOUCALT, 2009, p. 120). Com isso, consideramos gênero como um efeito do dispositivo da sexualidade: dimensão psicológica e cultural, inscrita nos corpos biológicos, construída social e historicamente, baseada em sentidos de feminino, masculino e seus estereótipos, e que envolve relações de poder nas diversas instituições sociais.

\section{Procedimentos metodológicos e resultados}

\footnotetext{
${ }^{7}$ Optamos por referenciar autoras e autores com nome e sobrenome. Consideramos esta opção uma tentativa de evidenciar os gêneros de pesquisadoras e pesquisadores e, por consequência, as mulheres na pesquisa, o que pode contribuir com o reconhecimento e a valorização da identidade feminina no campo e de forma mais ampla (PINHO; PULCINO, 2016).
} 
Esta pesquisa surge da vontade de observar a constituição do campo quanti-qualitativamente nos encontros ao longo dos anos. Feita de uma inspiração epistemológica em trabalhos sobre estado da arte na Educação (FERREIRA, 2002), mapeia e discute uma história da produção acadêmica nos eventos citados. As estratégias escolhidas e descritas abaixo, indicam a forma como foram selecionados os textos dos encontros, gerando, portanto, uma lente de análise dentre tantas lentes possíveis que poderiam ser estabelecidas. Para cada lente, "uma palavra excluída, substituída ou acrescentada a qualquer um dos resumos pode permitir que cada leitor faça uma apropriação diferente daquele texto" (FERREIRA, 2002, p. 268-9). Assim, assumimos previamente os limites em generalizar os resultados neste tipo de análise, mas afirmamos a importância de traça-los, por isso apresentamos os detalhes metodológicos realizados a fim de expor os caminhos tomados para que outros possam também percorrê-los e construir conosco essa visão generalista de nosso campo.

Nos seis primeiros encontros nacionais (MARANDINO et al., 2005; SELLES et al., 2007; VILELA, 2010; FERNANDES, 2012; FERNANDES, 2014, 2016) foram aprovados ao todo 2.517 trabalhos. Para selecionar as produções interessadas para esta pesquisa, elencamos 37 expressões que indicam palavras-chave ou seus radicais relacionados ao tema da sexualidade, do sexo e do gênero e elaboramos uma busca virtual em títulos, resumos e palavras-chave dos textos. Das palavras que elencamos, apenas 14 apresentaram resultados para esta pesquisa, conforme indicado na Tabela 1. Entretanto, esta estratégia não foi utilizada pra o I ENEBIO na medida em que os anais deste encontro não apresentam um mecanismo para busca de palavras. Nesse caso, todos os 283 textos aprovados para o I ENEBIO foram lidos e triados, resultando na seleção de 7 artigos. 
TABELA 1: Termos buscados nas edições do ENEBIO (2007-2016)

\begin{tabular}{|c|c|c|c|c|c|c|c|}
\hline \multirow{2}{*}{ Termos ${ }^{\dagger}$} & \multicolumn{5}{|c|}{ Edições do ENEBIO } & \multirow{2}{*}{ Total } & \multirow{2}{*}{$\begin{array}{c}\text { Percentagem } \\
(\%)\end{array}$} \\
\hline & II & III & IV & $\mathrm{V}$ & VI & & \\
\hline Sex- & 4 & 12 & 12 & 12 & 30 & 72 & 56,25 \\
\hline Gênero & 1 & 1 & 1 & 4 & 20 & 27 & 21,09 \\
\hline Corpo & 0 & 1 & 1 & 4 & 5 & 11 & 8,59 \\
\hline Reprodu- & 1 & 1 & 0 & 1 & 2 & 5 & 3,91 \\
\hline Gravidez & 1 & 1 & 0 & 0 & 1 & 3 & 2,34 \\
\hline Mulher & 0 & 0 & 0 & 1 & 1 & 2 & 1,56 \\
\hline Aborto & 0 & 0 & 0 & 0 & 1 & 1 & 0,78 \\
\hline AIDS & 0 & 0 & 1 & 0 & 0 & 1 & 0,78 \\
\hline DST & 1 & 0 & 0 & 0 & 0 & 1 & 0,78 \\
\hline Gameta & 0 & 0 & 1 & 0 & 0 & 1 & 0,78 \\
\hline Homossexual- & 0 & 0 & 0 & 1 & 0 & 1 & 0,78 \\
\hline LGBT & 0 & 0 & 0 & 0 & 1 & 1 & 0,78 \\
\hline Namoro & 0 & 0 & 1 & 0 & 0 & 1 & 0,78 \\
\hline Puberdade & 0 & 0 & 0 & 0 & 1 & 1 & 0,78 \\
\hline Total & 9 & 16 & 17 & 23 & 62 & 128 & 100,00 \\
\hline
\end{tabular}

Fonte: Elaboração própria.

$\dagger$ O hífen ao lado de algumas das palavras indica que estas foram consideradas como radicais e, portanto, englobam outras. Por exemplo, "sex-" se refere tanto a "sexualidade" como "sexual

Do total de trabalhos publicados nos anais dos demais encontros verificamos 128 pertencentes ao recorte temático sobre sexualidade estabelecido pelas expressões apresentadas na Tabela 1. Uma vez que alguns dos artigos encontrados continham mais de uma das palavras selecionadas, as recorrências foram eliminadas, de modo que o resultado se reduz para 100 artigos encontrados. Ao considerarmos as 7 produções selecionadas do I ENEBIO, chegamos a um recorte total de 107 textos (4,25\%) selecionados. O Gráfico 1 apresenta a distribuição desse total por cada ENEBIO, bem como indica a porcentagem relativa ao número total de trabalhos em cada encontro. 
GRÁFICO 1: Artigos selecionados nas edições do ENEBIO (2005-2016)

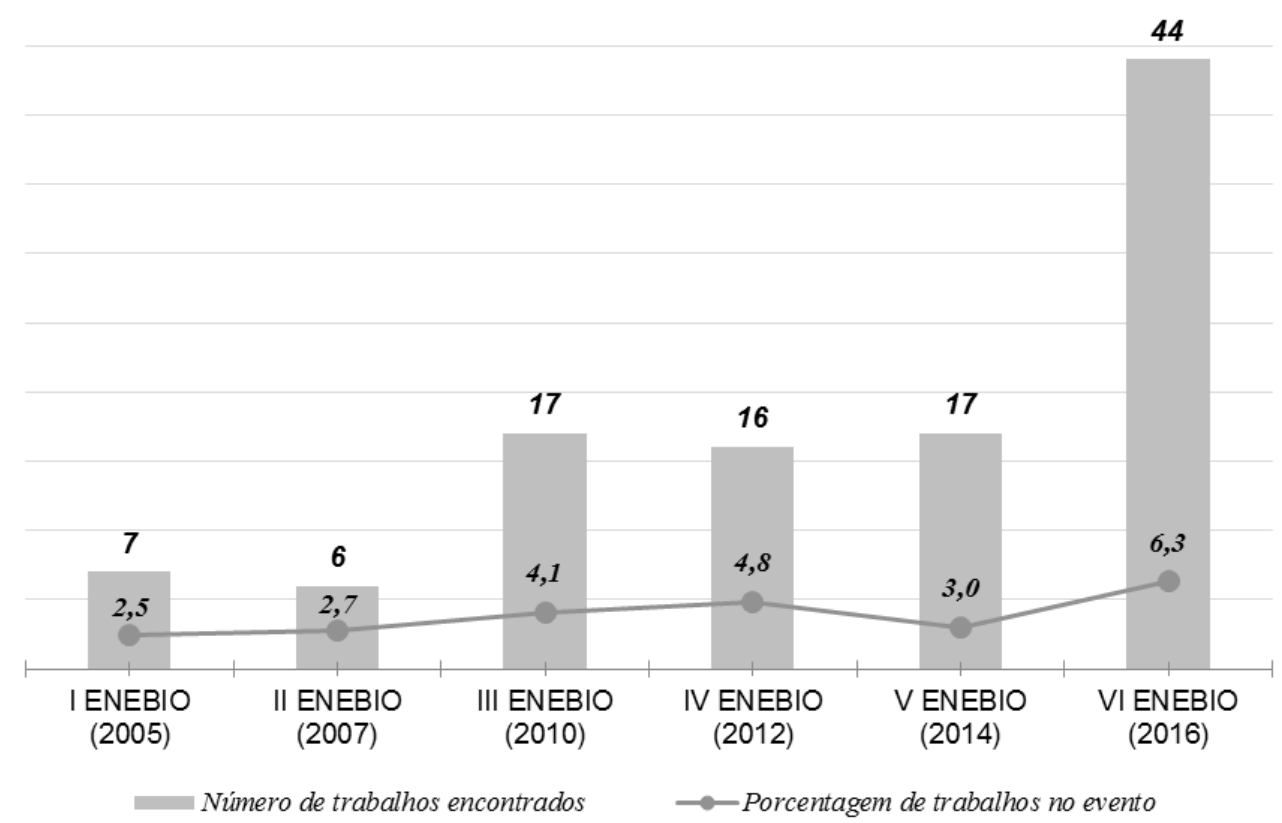

Fonte: Elaboração própria.

De acordo com o Gráfico 1, observamos um aumento de números de trabalhos apresentados ao longo das edições do encontro. Em 2005, no Rio de Janeiro, o encontro aprovou 283 produções, sendo 7 relacionados à sexualidade, o que equivale a 2,5\% do total. Em 2007, em Uberlândia, foram aprovados 219 artigos, dos quais 6 nos interessam, o que representa $2,7 \%$ do total. Em 2010, em Fortaleza, foram 417 trabalhos, dos quais 17 estão no recorte, isto é, 4,1\% do encontro. Em 2012, na edição de Goiânia, das 331 produções aprovados, 16 se enquadravam no recorte proposto, o que representa $4,8 \%$ do total. Entre estes quatro primeiros encontros observamos que a inserção do tema da sexualidade cresceu no percentual de pesquisas aprovadas nos encontros. Em 2014, em São Paulo, foram aprovados 568 textos, sendo 17 selecionados para análise, isto é, 3,0\% - uma queda em relação ao aumento gradual do tema no evento. Por fim, em 2016, houve um significativo aumento tanto na quantidade de pesquisas totais quanto no quantitativo voltado ao tema da sexualidade. Nessa edição, 
ocorrida na cidade de Maringá, 44 dos 699 trabalhos participantes discutiam sobre sexo, sexualidade e/ou gênero, o que representa $6,3 \%$ do total.

Os artigos submetidos são avaliados por um comitê científico formado por diversos pesquisadores, de modo que as dinâmicas de aceitação e rejeição dos trabalhos podem incidir em maiores ou menores percentuais em cada edição. É preciso considerar que os quantitativos de trabalhos aprovados podem refletir diversos processos e mecanismos de disputa no campo que não são claros apenas com tal exposição numérica dos textos selecionados. Entretanto, o crescimento quantitativo dos trabalhos relacionados a gênero e sexualidade aprovados ao longo destes seis encontros dá indícios da preocupação da organização do evento para com estas temáticas.

Para realizar a análise de trabalhos, construímos algumas categorias a partir das informações que o evento disponibiliza e buscamos as recorrências em: (i) gênero das autoras, (ii) instituição das autoras, (iii) objetos de análise, (iv) nível de ensino, e $(v)$ aspectos da sexualidade que apareciam nas produções.

\section{Discussão}

A Tabela 2 apresenta as ocorrências para cada categoria analisada. 
TABELA 2: Categorias de análise para os trabalhos selecionados

\begin{tabular}{c}
\multicolumn{2}{l}{ Categorias de análise } \\
\cline { 2 - 8 }
\end{tabular}

Fonte: Elaboração própria.

$\dagger$ Para as categorias Gênero e Instituição, o percentual foi encontrado pela razão entre a soma total da subcategoria e a soma total nos eventos, por exemplo: para saber a porcentagem de autoras, é a razão entre 219 e 311. Assim, 70,42\% das pessoas eram mulheres. Para as categorias Objetos de análise, Nível de Ensino e Aspectos, o percentual foi encontrado pela razão entre a soma total da subcategoria e o total de trabalhos analisados, por exemplo: para saber a porcentagem de trabalhos que realizaram a pesquisa com licenciandas, faz-se a razão entre 9 e 109 totais. Então, 8,41\% dos trabalhos investigaram práticas, experiências e saberes de licenciandas. Por essa diferença de cálculo, alguns percentuais ultrapassam 100\% quando somados. 
No que diz respeito ao gênero dos pesquisadores, verificamos uma predominância autoral feminina $(70,42 \%)$ em relação às masculina $(29,58 \%)$. É importante considerar que estes valores foram calculados em função da autoria de cada artigo e, por isso, expressa a participação total nos textos e não no evento. Esta proporção parece se manter se comparada à totalidade de artigos selecionados pelos encontros: verificamos a autoria total - ou seja, não apenas dos textos selecionados para essa pesquisa, mas da totalidade de trabalhos apresentados - dos I e IV encontros ${ }^{8}$ e identificamos valores aproximados (as autorias femininas correspondem a 70,38\% e 70,21\% respectivamente). Ao passo em que estes valores são aproximados, não podemos inferir correlação entre a maior participação feminina em textos sobre gênero e sexualidade e o tema destes trabalhos. Entendemos que a maior participação das mulheres nas edições deste evento se dá possivelmente em função da ocupação majoritariamente feminina do magistério (DE SÁ; ROSA, 2004) e ao ethos da profissão, isto é, práticas e significados relacionados ao universo feminino (CARVALHO, 1999).

As universidades públicas $(78,36 \%)$ se configuram como principal locus de produção pesquisas sobre sexualidade para este evento em comparação a unidades privadas $(5,85 \%)$ e instituições de educação básica $(12,87 \%)$.

O desenvolvimento de uma nova cultura profissional dos professores passa pela produção de saberes e de valores que deem corpo a um exercício autónomo da profissão docente. [...]. A organização das escolas parece desencorajar um conhecimento profissional partilhado dos professores, dificultando o investimento das experiências significativas nos percursos de formação e a sua formulação teórica. (NÓVOA, 1992, p. 25)

\footnotetext{
${ }^{8}$ Os anais dos outros encontros, disponibilizados online, não apresentam sumário que permita a busca geral pelos autores.
} 
Assim como Nóvoa (1992), Monteiro (2001) aponta a necessidade de repensar a atuação docente, reposicionando as professoras da escola enquanto produtoras de um saber sui generis que irá compor o que entendemos como conhecimento escolar, tão legítimo quanto os conhecimentos acadêmicos. Além das universidades ocuparem tradicionalmente o lugar de produção do conhecimento, parece haver um entrave das próprias escolas em incentivar e apoiar as professoras neste percurso. Em geral, o ambiente de trabalho das professoras da educação básica valoriza aspectos da ação em sala de aula, sendo muito comuns as queixas sobre falta de tempo para reflexão e produção dos seus materiais didáticos. Se a carga de trabalho das professoras se concentra dentro da sala de aula, pouco tempo acaba sendo fornecido para, por exemplo, realizarem trocas de experiências em congressos como o ENEBIO.

As universidades são o principal espaço de produção acadêmica, mas as pesquisas se utilizam do ensino básico como foco $(67,29 \%)$, além de pouco mais da metade ter como objeto de análise as atrizes da escola (55,14\%). Esta percepção reitera achados obtidos em pesquisas anteriores (PINHO; BASTOS, 2016, p. 5601), no qual percebemos haver "uma distância entre a pesquisa e a professora da educação básica: quem está no cotidiano escolar não pesquisa e quem pesquisa não está na escola”. Por isso, indicamos novamente que além dos saberes da sala de aula estarem presentes nos encontros através da reflexão sobre dados empíricos, nos parece necessário "que sejam também as professoras em exercício a fazê-lo, ou seja, valorizar o papel das professoras na divulgação de seus conhecimentos e saberes" (PINHO; BASTOS, 2016, p. 5602).

Os trabalhos que apresentam recorte no ensino superior (11,21\%) buscam explicar elementos da formação docente através da análise de práticas, experiências e discursos das licenciadas, egressas e professoras da educação básica $(8,24 \%)$. De todos os textos analisados, apenas um realizou entrevistas com professoras universitárias (0,93\%). Este dado indica uma lacuna importante para as pesquisas sobre o ensino de Biologia em 
articulação com gênero e sexualidade: carecem pesquisas dos saberes docentes de professoras universitárias. Acreditamos que esta é uma área promissora, na medida em que essas pesquisas podem contribuir diretamente com análises sobre o saber e o fazer das professoras que formam as professoras da educação básica, valorizando observações e experiências relatadas pelas professoras universitárias.

No que diz respeito aos sentidos de sexualidade, optamos por construir quatro grandes categorias analíticas: biológica, sociológica, psicológica e ética. Ao ler os artigos, entendemos por sentido biológico aqueles que abordam corpo, sistema reprodutor, saúde individual, saúde coletiva, doenças e profilaxia, DST/AIDS, menstruação, concepção, gravidez e contracepção. O sentido sociológico é relativo às abordagens de gênero, orientação sexual, movimentos sociais, identidade, diferença, diversidade, interseccionalidade, mídia, família, processos históricos, rituais, casamento e religião. O sentido psicológico é aquele em que consideramos as discussões sobre relacionamentos, emoções, prazer, orgasmo, masturbação, comportamentos e autoestima. Enfim, o sentido ético dá ênfase a valores, diálogo, respeito, solidariedade, preconceito, regras morais, aborto, liberdade sexual, estupro e tabus. Esta diversidade de sentidos valorizados pelo ENEBIO já havia sido verificada por Etter e colaboradoras (2014, p. 2090):

É nesse contexto que procuramos compreender os sentidos de 'sexualidade' produzidos no conjunto dos textos levantados, considerando a diversidade de influências que constroem as ideias e visões de seus autores, ora tendendo mais para perspectivas do campo da saúde e da Biologia, ora estabelecendo relações com outras perspectivas de caráter mais social e/ou cultural sobre o tema.

Ainda que a diferença seja pequena, observamos mais trabalhos que levantam aspectos sociológicos para compreender a sexualidade $(87,85 \%)$ do 
que para aspectos biológicos (84,11\%). A prevalência nos aspectos culturais pode ser fruto de um investimento do campo olhar para si próprio como espaço de produção de conhecimento em meio a disputas com outros conhecimentos, ou seja, pode ser fruto de uma perspectiva pós-positivista que assume a subjetividade do processo de produção científico (PHILLIPS; BURBULES, 2000). O que vimos nesses textos é justamente uma crítica ao campo das Ciências Biológicas, que vem tradicionalmente (re)produzindo uma suposta neutralidade científica, especialmente diante assuntos que envolvem aspectos sociais e culturais.

Em alguns trabalhos não observamos nenhuma perspectiva de análise ancorada ao ensino de biologia. Tais artigos apresentam práticas de ensino de biologia, mas não discutem sobre o ensinar biologia. Esta é uma distinção importante de se fazer: há os trabalhos que servem de inspiração para o ensino, mas há aqueles que questionam e problematizam o ensinar biologia, que analisam tal ensino à luz das perspectivas das Ciências Sociais (FIGUEIREDO, 2016; RUFATO; BIZERRA, 2014; COELHO e CAMPO, 2012).

Também aparecem de forma significativa elementos da dimensão psicológica (71,96\%). O sentido psicológico para a sexualidade nos fornece caminhos para além dos discursos deterministas da sexualidade enquanto resposta unicamente biológica ou social. Trazer a psicologia e suas reflexões sobre a subjetividade humana (CASSAL, GARCIA e BICALHO, 2011) para a biologia contribui na construção multidimensional dos saberes sobre a sexualidade.

Por fim, apontamos a presença de uma reflexão ética em $62,62 \%$ dos trabalhos analisados. Pensar a sexualidade enquanto um dispositivo, como nos convida Michel Foucault (2009; 2000), é entendê-la enquanto um conjunto de discursos, práticas e instituições que se modifica ao longo do tempo e atua no gerenciamento e controle de corpos, de modos de ser e das populações. Acreditamos que refletir eticamente sobre o dispositivo da sexualidade convida a interlocutora a pensar o ensino de biologia como um 
campo capaz de produzir práticas que combatam preconceitos, discriminações e violências contra aqueles sujeitos que não obedecem aos padrões da heteronormatividade (BENTO, 2006).

\section{Considerações finais}

De que forma essas reflexões contribuem para pensar a educação em Ciências e a sexualidade? Primeiro, esta análise nos ajuda a entender de que forma a área de ensino de Biologia se debruça sobre suas questões, sendo útil para pesquisadoras e professoras universitárias que participam da produção acadêmica e da formação docente. Entendemos que esta é uma contribuição para reflexão do campo sobre ele próprio: Que questões estão postas? Que temas estão surgindo e se fortalecendo? E que temas deixam de ser foco de interesse? O que inquieta o campo? Que respostas o campo produz para orientar tais inquietações?

Segundo, nossas análises são igualmente úteis às professoras que atuam diretamente no ensino de Biologia, uma vez que o processo formativo é contínuo. Por isso, observar novas questões do campo que não estiveram presentes na formação destas professoras ou verificar novas respostas para as dinâmicas da sala de aula ao trazer exemplos de práticas ou novo aporte teórico ainda não explorado pode levar a uma maior consciência sobre essa rede de relações de saber e poder que as constitui profissionalmente.

Diante dos achados apresentados, reconhecemos que há uma forte disputa entre as áreas do conhecimento em torno da sexualidade. Tal como verificado em outros encontros acadêmicos de ensino de Ciências e Biologia (BASTOS; PINHO, 2017; PINHO e BASTOS, 2016), os trabalhos apresentados no ENEBIO tendem a valorizar os aspectos biológicos e sociológicos para analisar a relação entre o ensino de Biologia e a sexualidade. Com menos força estão as produções que priorizam aspectos éticos, ou seja, aqueles que entendemos que podem fornecer suportes 
didáticos para agir sobre os problemas e conflitos que emergem sobre sexualidade no contexto escolar.

Ao operar com temas afins à sexualidade, estes trabalhos do ensino de Biologia produzem sentidos e disputas epistemológicas no jogo de poder do espaço acadêmico-científico. Propomos então a continuidade da análise do campo sobre o próprio campo e, como nos parece que vem acontecendo nas edições do ENEBIO, um olhar multidimensional para os temas de sexualidade para a formação e capitação docente, que, ao contrário de uma proposta epistemológica ingênua, é uma aposta de que somente o esforço de conciliação de diversas explicações é possível para dar conta de um tema tão complexo.

\section{Referências}

BASTOS, F. "A diretora sabe que você está trabalhando isso na sala de aula?" Diversidade sexual e ensino de ciências. Dissertação (Mestrado). Departamento de Educação, Pontifícia Universidade Católica do Rio de Janeiro, Rio de Janeiro, 2015.

.; PINHO, R. Sentidos de sexualidade nos anais dos Encontros Nacionais de Pesquisa em Educação em Ciências (1997-2015). Anais do XI Encontro Nacional de Pesquisa em Educação em Ciências - XI ENPEC, UFSC, Florianópolis, 2017.

BENTO, B. Corpos e próteses: dos limites discursivos do dimorfismo. Anais do Seminário Internacional Fazendo Gênero 7: Gênero e Preconceito, Santa Catarina, 2006. Disponível em: <http://www.fazendogenero7.ufsc.br/>. Acesso em: 20 jun. 2010.

CARVALHO, M. No coração da sala de aula: gênero e trabalho docente nas séries iniciais. São Paulo: Xamã, 1999.

CASSAL, L.; GARCIA, A.; BICALHO, P. Psicologia e o dispositivo da sexualidade: biopolítica, identidades e processos de criminalização. PSICO, Porto Alegre, v. 42, n. 4, pp. 465-473, 2011.

COELHO, L.; CAMPOS, L. Diversidade sexual e licenciandos em ciências biológicas: que professor formamos? Revista da SBEnBio, Niterói, v. 5, p. 1-10, 2012.

DE SÁ, C. M.; ROSA, W. M. A história da feminização do magistério no Brasil: uma revisão bibliográfica. Anais do III Congresso Brasileiro de História da Educação, PUC-PR: 2004. 
ETTER, F.; ALVES, L.; FERREIRA, M. S.; GOMES, M. M. Sentidos de sexualidade em produções acadêmicas: investigando os anais dos encontros nacionais de ensino de biologia (2005-2012). Revista da SBEnBio, Niterói, v. 7, 2014.

FERNANDES, J. A. (Org.) Anais do IV ENEBIO, II EREBIO MG/TO/GO/DF. Repensando a experiência e os novos contextos formativos para o Ensino de Biologia, Goiânia, 2012. Revista da SBEnBio, Campinas, v. 5, 2012.

. (Org.) Anais do V ENEBIO, II EREBIO SP/MT/MS. Entrelaçando histórias, memórias e currículo no Ensino de Biologia, São Paulo, 2014. Revista da SBEnBio, Niterói, v. 7, 2014.

. (Org.) Anais do VI ENEBIO, III EREBIO PR/SC/RS. Políticas Públicas Educacionais - Impactos e Propostas ao Ensino de Biologia, Maringá, 2016. Revista da SBEnBio, Niterói, v. 9, 2016.

FERREIRA, N. S. As pesquisas denominadas "estado da arte". Educação \& Sociedade, n. 79, p. 257-272, 2002.

FIGUEIREDO, B. A. Delineamentos dos papéis sociais de gênero por estudantes do ensino médio. Revista da SBEnBio, Niterói, v. 9, p. 2267-2277, 2016.

FOUCAULT, M. História da Sexualidade I: A vontade de saber. Rio de Janeiro: Edições Graal, 2009. Microfísica do poder. Rio de Janeiro: Graal, 2000.

MARANDINO, M. et al. (Org.) Anais do I ENEBIO, III EREBIO RJ/ES. Ensino de Biologia: conhecimentos e valores em disputa. Rio de Janeiro: SBEnBio, 2005.

MONTEIRO, A. Professores: entre saberes e práticas. Educação \& Sociedade, v. 22, n. 74, p. 121-142, 2001.

NÓVOA, A. Formação de professores e profissão docente. In: professores e a sua formação. Lisboa: Dom Quixote, 1992. P. 13-33. (Coord.) Os

PHILliPS D. C., BURBULES N. C. Can, and Should, Educational Inquiry Be Scientific? In: Postpositivism and Educational Research. Rowman \& Littlefield Publishers, p. 65-95, 2000.

PINHO, R.; BASTOS, F. Sentidos de sexualidade nos anais dos Encontros Regionais de Ensino de Biologia RJ/ES (2001-2015). Revista da SBEnBio, Niterói, v. 9 , p. $5594-5606,2016$.

PINHO, R.; PULCINO, R. Desfazendo os nós heteronormativos da escola: contribuições dos estudos culturais e dos movimentos LGBTTT. Educação $e$ Pesquisa, São Paulo, v. 42, n. 3, p. 665-680, 2016.

RUFATO, B. P.; BIZERRA, A. F. Pais e mães em visita a museus de ciências no Brasil: há diferenças? Revista da SBEnBio, Niterói, v. 7, p. 962-973, 2014. 
SELLES, S. et al. (Org.) Anais do II ENEBIO, I EREBIO MG/TO/GO/DF. Os dez anos da SBEnBio e o ensino de Biologia no Brasil: história entrelaçadas. Uberlândia: SBEnBio, 2007.

VILELA, M. (Org.) Anais do III ENEBIO, IV EREBIO NE. Temas polêmicos e ensino de Biologia, Fortaleza, 2005. Revista da SBEnBio, Campinas, v. 3, 2010.

Recebido em março de 2018.

Aprovado em dezembro de 2018. 
Anexo 1: Informações sobre os encontros realizados de 2001 a 2016

\begin{tabular}{|c|c|c|c|c|c|}
\hline Regional & EREBIO & ENEBIO & Ano & Local & Endereço eletrônico ${ }^{\dagger}$ \\
\hline \multirow{2}{*}{$\begin{array}{l}\text { Regional 1: } \\
\text { SP/MT/MS }\end{array}$} & $\mathrm{I}$ & & 2006 & São Paulo & Disponível apenas em $C D$ \\
\hline & II & $\mathrm{V}$ & 2014 & São Paulo & $\begin{array}{l}\text { http://www.sbenbio.org.br/blog/revista } \\
\text {-sbenbio-edicao-7I }\end{array}$ \\
\hline \multirow{7}{*}{$\begin{array}{l}\text { Regional 2: } \\
\text { RJ/ES }\end{array}$} & I & & 2001 & Niterói & $\begin{array}{l}\text { http://www.sbenbio.org.br/regional2/a } \\
\text { rquivos/anais_I_erebio.pdf }\end{array}$ \\
\hline & II & & 2003 & São Gonçalo & $\begin{array}{l}\text { http://www.sbenbio.org.br/regional2/a } \\
\text { rquivos/anais_II_erebio.pdf }\end{array}$ \\
\hline & III & $\mathrm{I}$ & 2005 & $\begin{array}{l}\text { Rio de } \\
\text { Janeiro }\end{array}$ & $\begin{array}{l}\text { https://sbenbio.org.br/wp- } \\
\text { content/uploads/anais/anais_I_enebio } \\
\text { III_erebio.pdf }\end{array}$ \\
\hline & IV & & 2007 & Seropédica & $\begin{array}{l}\text { http://rmoraisconsultoria.com/erebio/a } \\
\text { rquivos/2007/erebio2007.swf }\end{array}$ \\
\hline & $\mathrm{V}$ & & 2010 & Vitória & $\begin{array}{l}\text { http://rmoraisconsultoria.com/erebio/a } \\
\text { rquivos/2010/erebio2010.swf }\end{array}$ \\
\hline & VI & & 2012 & $\begin{array}{l}\text { Rio de } \\
\text { Janeiro }\end{array}$ & $\begin{array}{l}\text { http://rmoraisconsultoria.com/erebio/a } \\
\text { rquivos/2012/erebio2012.swf }\end{array}$ \\
\hline & VII & & 2015 & Niterói & $\begin{array}{l}\text { http://www.sbenbio.org.br/regional2/a } \\
\text { rquivos/anais_VII_erebio.pdf }\end{array}$ \\
\hline \multirow{8}{*}{$\begin{array}{l}\text { Regional 3: } \\
\text { PR/SC/RS }\end{array}$} & $\mathrm{I}$ & & 2005 & Curitiba & Indisponível \\
\hline & II & & 2006 & Florianópolis & $\begin{array}{l}\text { Endereço eletrônico } \\
\text { (http://www.erebiosul2. } \\
\text { ufsc.br/index.htm) indisponivel }\end{array}$ \\
\hline & III & & 2008 & Ijuí & $\begin{array}{l}\text { http://www.sbenbio3.ufsc.br/wp/sbenb } \\
\text { io/III-EREBIO-Unijui-2008.rar }\end{array}$ \\
\hline & IV & & 2010 & Chapecó & $\begin{array}{l}\text { http://www.sbenbio3.ufsc.br/wp/sbenb } \\
\text { io/IV-EREBIO-Unochapeco-2010.rar }\end{array}$ \\
\hline & $\mathrm{V}$ & & 2011 & Londrina & $\begin{array}{l}\text { http://www.uel.br/ccb/biologiageral/ev } \\
\text { entos/erebio/erebio.htm }\end{array}$ \\
\hline & VI & & 2013 & Santo Ângelo & $\begin{array}{l}\text { http://santoangelo.uri.br/erebiosul201 } \\
\text { 3/anais/ }\end{array}$ \\
\hline & VII & & 2015 & Criciúma & $\begin{array}{l}\text { http://www.unesc.net/portal/capa/inde } \\
\mathrm{x} / 497\end{array}$ \\
\hline & VIII & VI & 2016 & Maringá & $\begin{array}{l}\text { http://www.sbenbio.org.br/blog/renbio- } \\
\text { edicao-9/ }\end{array}$ \\
\hline \multirow{3}{*}{$\begin{array}{l}\text { Regional 4: } \\
\text { MG/GO/TO } \\
\text { /DF }\end{array}$} & I & II & 2007 & Uberlândia & $\begin{array}{l}\text { http://www.sbenbio.org.br/cds/2enebio } \\
\text { lindex.swf }\end{array}$ \\
\hline & II & IV & 2012 & Goiânia & $\begin{array}{l}\text { http://www.sbenbio.org.br/cds/4enebio } \\
\text { lindex.html }\end{array}$ \\
\hline & III & & 2015 & Juiz de Fora & $\begin{array}{l}\text { http://www.sbenbio.org.br/blog/anais- } \\
\text { do-encontro-regional-de-ensino-de- } \\
\text { biologia-regional-4/ }\end{array}$ \\
\hline \multirow{6}{*}{$\begin{array}{l}\text { Regional 5: } \\
\text { Nordeste }\end{array}$} & $\mathrm{I}$ & & 2003 & $\begin{array}{l}\text { Feira de } \\
\text { Santana }\end{array}$ & $\begin{array}{l}\text { Endereço eletrônico } \\
\text { (http://www.sbenbio.org.br/regional5/1 } \\
\text { erebio.html) indisponível }\end{array}$ \\
\hline & II & & 2006 & João Pessoa & $\begin{array}{l}\text { Endereço eletrônico } \\
\text { (http://www.ce.ufpb.br/ce/erebio/event } \\
\text { o.html) indisponível }\end{array}$ \\
\hline & III & & 2008 & Pernambuco & $\begin{array}{l}\text { http://docplayer.com.br/29860790- } \\
\text { Ensino-de-biologia-meio-ambiente-e- } \\
\text { cidadania-olhares-que-se-cruzam-2- } \\
\text { ed-revista-e-ampliada.html }\end{array}$ \\
\hline & IV & III & 2010 & Fortaleza & $\begin{array}{l}\text { http://www.sbenbio.org.br/cds/3enebio } \\
\text { lindex.html }\end{array}$ \\
\hline & $\mathrm{V}$ & & 2013 & Natal & http://www.sbenbio.org.br/verebione/ \\
\hline & VI & & 2015 & $\begin{array}{l}\text { Vitória da } \\
\text { Conquista }\end{array}$ & $\begin{array}{l}\text { https://proceedings.galoa.com.br/erebi } \\
\text { o-ne/trabalhos?lang=pt-br }\end{array}$ \\
\hline
\end{tabular}

Fonte: Elaboração própria.

$\dagger$ Consideramos incluir os links para os anais dos eventos porque nem todos estão disponíveis. Foi necessário usar diferentes combinações de palavras no site de buscas Google e entrar em contato com membros das comissões organizadoras para se chegar a alguns links e/ou ter certeza da indisponibilidade. 